International Journal of Social Science and Economic Research

ISSN: 2455-8834

Volume:06, Issue:07 "July 2021"

\title{
LEARNING CHINESE IN EARLY CHILDHOOD BASED ON CONSTRUCTIVISM LEARNING THEORY
}

\author{
Phakwipa Chaikeawmay ${ }^{1}$, Assoc.Prof. Ratana Na Lamphun ${ }^{2}$ and Dr. Ken Kemp ${ }^{3}$ \\ ${ }^{1}$ Master of Education Program in Development Education, Graduate School, Chiang Mai University. \\ ${ }^{2}$ Associate Professor, Master of Cultural Studies Program, Faculty of Humanities, Chiang Mai \\ University. \\ ${ }^{3}$ Lecturer, Master of Education Program in Development Education, Faculty of Education, Chiang Mai \\ University
}

DOI: 10.46609/IJSSER.2021.v06i07.022 URL: https://doi.org/10.46609/IJSSER.2021.v06i07.022

\begin{abstract}
This qualitative research aimed to study Chinese language learning process and reflection in learning Chinese of early childhood based on the theory of Constructivism. The target group included 15 third year kindergarten students, 2nd semester of the 2016 academic year, Waraneekul Kindergarten School, Saraphee District, Chiang Mai Province.The research is qualitative based on the paradigm of interpretation. The tools are Chinese language lesson plans for third year kindergarten of Waraneekul Kindergarten School, total of five subjects (numbers, parts of the body, animals, the sky, family), each with two totally ten lesson plans and interview forms of self-knowledge creation process on each subject individually. The results showed that the Chinese language learning process of early childhood was derived from previous experience, prior knowledge together with new experience and new knowledge. This makes it possible to acquire a unique process of creating knowledge of the learners depending on the interaction with the surrounding things. Moreover, Chinese is the language that comes from pictures which enable early learners to imagine different images depending upon their individual background, leading to different reflection on their thought, culture, values, and the use of language in accordance with Vygotsky's theory of Social Constructivism.
\end{abstract}

Keywords: Learning, Chinese Language, Early Childhood, Constructivism

\section{Introduction}

Chinese is one of the more increasingly popular foreign languages. It is accepted that at present People's Republic of China has a very important influence and role in politics, trade and economy. Also joint venture in various business between Thailand and People's Republic of China has respectively increased since the establishment of diplomatic relations between them in 


\section{International Journal of Social Science and Economic Research}

ISSN: $2455-8834$

Volume:06, Issue:07 "July 2021"

1975. In the later period, it also resulted in educational institutions at various levels both public and private in Thailand. More Chinese language courses have been organized since 1992 as Chinese language teaching is allowed to operate freely like other foreign languages. (Masantisuk, 2008).

The Ministry of Education (2003) has included Chinese language in Foreign Language Department that learners can choose to learn according to the 2001 Basic Education Curriculum encouraging primary and secondary schools to offer Chinese language courses widely. Moreover, scholars are of the opinion that language is a complex system. It is an important tool for intellectual development of early childhood children (Niyomtham \& Niyomtham, 1997). Language learning should begin at the age of 0-6 years old which is the most important and necessary foundation for intellectual and human potential development. Therefore, many kindergartens have opened Chinese as their one more language.

Kindergartens in Thailand still have no perfect Chinese language course or model for early childhood education. The curriculum used in some schools is activity-oriented. Some focus on conversation or use Chinese language textbooks for early childhood made by educational institutions in People's Republic of China such as Waraneekul Kindergarten School, Saraphee District, Chiang Mai Province. Teachers will use the textbook as a guideline to teach early childhood children along with monitoring the development of their learning. According to Bruner (cited in Thamboworn, 2006), children's learning development is classified into three stages: learning by doing, by watching / imagining and by using symbols as well as applying the concept of Dewey (1973) which believed that learning must go hand in hand with experience emphasizing that learners' learning arises from linking old experiences with new ones.

Early childhood children can learn languages quickly with their language learning development different from that of adults. As a result of the children's intellectual maturity level is not fully developed. Still, they can't think of something abstract, can't use all parts of language development in its entirety. These abilities depend on their level of development at each age. Moreover, language has abstract properties, special symbols must consequently be used to represent the meaning of reading and writing. Young children will learn language by hearing, listening to talks from parents, caregivers, or from daily life at home. When at school, they will learn from teachers and related people by imitating the sounds heard from others first. Words are collected and rules are created by combining the accumulated words to make sounds and develop further. As they grow up, the accumulation of more and more words will be increased and tied up into a sentence according to the steps or the development of their language learning. However, in order to learn language to their development, parents, teachers, guardians or related persons must organize language experiences to be meaningful to children including seeking ways 
International Journal of Social Science and Economic Research

ISSN: 2455-8834

Volume:06, Issue:07 "July 2021"

to promote a variety of language learning to suit their individual difference to enable them to learn language with highest efficiency (Iamsa-At, 2005).

In accordance with the concept of Vygotsky's Constructivism (Wing \& Putney, 2002), it believed that every learner who understands about learning new matters will be based on his prior knowledge. Therefore, the learner's previous experience is a very important factor for learning. Khaemmanee (2011) explained that the real learning process of the learners is not caused by the teacher's telling or that their duty is only to remember the concepts being told, but is the learning process where learners understand and recognize that knowledge meaningfully in order to create their own knowledge and store in the brain for a long time to connect knowledge and for further use.

The researcher studied Chinese language learning for early childhood children based on the theory of Constructivism and used it to study the learning process and reflection in Chinese learning of early childhood children. In this, the researcher focuses on the interpretation paradigm as well as presents the content by analytical and descriptive method

\section{Research Objectives}

1. To study Chinese language learning process of early childhood according to the theory of Constructivism.

2. To study reflection on Chinese learning of early childhood according to the theory of Constructivism.

\section{Research Procedure}

This is a qualitative research. The researcher has determined procedure of conducting it as follows

Step 1: The researcher chooses Waraneekul Kindergarten School, Saraphee District, Chiang Mai Province for the research since it is a three-language school : Thai, Chinese and English from one to three kindergarten levels.

Step 2: Study of documents and researches related to Chinese teaching and learning for early childhood and the theory of Constructivism.

Step 3: Formation of Research Tools

1. The research instruments consist of 


\section{International Journal of Social Science and Economic Research}

ISSN: $2455-8834$

Volume:06, Issue:07 "July 2021"

1.1 Chinese language for early childhood lesson plans based on the theory of Constructivism have been made step by step as follows

1.1.1 Study the documents on the process of making lesson plans based on those of Waraneekul Kindergarten School.

1.1.2 Create Chinese language for early childhood lesson plans based on Constructivism consisting of 5 subjects: numbers, parts of the body, animals, the sky, and family with 2 plans of each subject (total of 10 plans) which lasts 40 minutes according to the schedule of Waraneekul Kindergarten School.

1.1.3 Present them to experts who are Head of Kindergarten, Head of Academic Affairs and Director of Waraneekul Kindergarten School to consider and verify conformity, accuracy of the Chinese language for early childhood lesson plans based on Constructivism, purpose and language suitability.

1.1.4Revise the lesson plans according to expert recommendation and conduct experiments with the target group.

1.2 Develop interview form based on the concept of Constructivism of Vygotsky (Wing \& Putney, 2002). It is the interview which the researcher interviews and notes down every time after the completion of the teaching and learning process to know what the learners have said or done reflects on them.

1.2.1 Study the concept of Vygotsky's Constructivism and the conceptual framework of the research to define interview issues.

1.2.2 Give the interview form to three experts to examine to be correct and appropriate after that to improve and check for content validity.

1.2.3 Give the reflection made and revised according to the suggestion of the experts to recheck the accuracy by the advisor again, then have the learners try it and present the result to the advisor.

1.2.4 Apply the revised learning process analysis based on Constructivism concept to the target group.

1.2.5 Use the information from the target group to make an interview according to Constructivism to study learners' reflection to lead to the second purpose of the research.

Step 4 Collection of Information 


\section{International Journal of Social Science and Economic Research}

ISSN: $2455-8834$

Volume:06, Issue:07 "July 2021"

The researcher collects the research data as follows

1. Apply the Chinese language for kindergarten level lesson plans of Waraneekul Kindergarten School to the target group where there are fifteen learners studying in Kindergarten $3 / 2$ in the second semester of the academic year 2016.

2. After the target group has learned to the Chinese language for early childhood lesson plan. The researcher will interview the sample group individually together with audio record and collect the interview to know how each learner has the process of creating knowledge of each Chinese character and record the data in the conceptual learning process analysis form and interview form of Constructivism theory. If any learners are still unable to build knowledge themselves, the researcher must find methods or materials to guide, encourage them to build their own knowledge of that subject for the second time.

3. The researcher records the data in the interview form to the concept of Constructivism after all five subjects are completed.

\section{Research Results}

The researcher would like to present the results of Chinese learning for early childhood based on Constructivism theory total of five subjects, namely, numbers, parts of the body, animals, the sky and family in the following order.

\section{Numbers (characters of number 1-10)}

The first Chinese character - (E), one. Out of fifteen learners, eight use their previous knowledge to answer that it is Chinese number one with one line. Two learners have built their knowledge by observing at the time the teacher teaches that the Chinese number one writing style is one line but a horizontal one, and two learners compare the characteristics they see to the Chinese number one character to create knowledge and the other three learners interact with things around them to create knowledge.

The next character is 二 (Uh), two. Out of fifteen, seven learners build their knowledge of number two by observing the teacher who teaches that the Chinese character for number two has two lines. Two children build their knowledge by reasoning to correlate with number two where there are two things. Chinese number two then has two lines, short at the top and long at the bottom. Two learners use their previous knowledge to compare with new one to create knowledge, the other six learners compare the characteristics of what they see with the Chinese number two character to create knowledge. 


\section{International Journal of Social Science and Economic Research}

ISSN: $2455-8834$

Volume:06, Issue:07 "July 2021"

The next character is $三$ (Sun), three. Out of fifteen, five learners build their knowledge of number three by observing the teacher saying that it has three lines. Two learners build their knowledge of Chinese number three by using their prior knowledge comparing with the new one. The other eight learners make their symbols comparing to the Chinese number three which they have ever seen to help remember it.

The next character is 四 (Sue), four. Out of fifteen learners, three build their knowledge of Chinese number four by observing the teacher who teaches to write it in line order, then they can memorize it. Two learners build their number four recognition by making an imaginative storytelling. The other ten build their Chinese number four recognition knowledge by making a story based on what they have interacted and encountered in daily life to make their selfknowledge.

The next character is 五 (U), five. Out of fifteen, eight learners build their knowledge of Chinese number five by observing the teacher who teaches them to write it in line order to remember to create knowledge. Five learners create the Chinese number five symbol which they have always seen to help memorize it. The other two memorize the number from what they interact in their daily life to create their own knowledge.

The next character is 六 (Liu), six. Out of fifteen, six learners build up the Chinese number six by observing the teacher who teaches to write it in line order and then memorize it. Seven learners build knowledge of the Chinese number six by making an imaginative story that they have ever seen in relation to it. The other two create symbols comparing Chinese number six with what they have seen to help memorize it.

The next character is $七$ (Chee), seven. Out of fifteen, eleven learners build knowledge of Chinese number seven by observing the teacher who writes it in line order after that memorize it comparing with previous knowledge then create a picture in the brain. The other four learners build knowledge by creating symbols comparing the Chinese number seven with what they have seen to help remember it

The next character is 八 (Pa), eight. Out of fifteen learners, twelve build the knowledge of Chinese number eight by observing the teacher who teaches to write it in line order after that memorize it to create knowledge, compares with the previous knowledge and then creates a picture in the brain. The other three learners build knowledge by creating symbols comparing the Chinese number eight with what they have seen to help remember it. 


\section{International Journal of Social Science and Economic Research}

ISSN: $2455-8834$

Volume:06, Issue:07 "July 2021"

The next character is 九 (Jiu), nine. Out of fifteen, ten learners build their knowledge by creating symbols comparing the Chinese number nine with what they have seen to help remember it. The other five build knowledge by creating a story in relation to the Chinese number nine character by making an imagination which they have seen to create knowledge by themselves.

The last character is + (Sue), ten. Out of fifteen learners, fourteen build the knowledge of Chinese number ten by observing the teacher who has taught to write the Chinese number ten in line order then memorize it to create knowledge comparing with previous knowledge and create a picture in the brain. The other learner builds knowledge by creating a symbol comparing the Chinese number ten with what he has seen to help him remember it.

\section{Parts of the Body}

The first character is 眉 (Mei), eyebrow. From fifteen learners, seven build their own knowledge from the interpretation of existing knowledge with previous experiences, reasoning to help remember the meaning of Chinese character. Three learners build their knowledge by using family interaction to create a story related to the Chinese characters to help remember the meaning. The other five learners build the knowledge of remembering 眉 (eyebrow) by making a story in relation to the Chinese characters by which they make an imagination from what they have ever seen to create their own knowledge.

The next character is 目 $(\mathrm{Mu})$, eye. From fifteen, nine learners compare the characteristics of the Chinese characters $\mathrm{Mu}$ with the pictures they have seen to help remember the meaning. Two learners build their own knowledge by interpreting the meaning of existing knowledge with previous experiences reasoning to help remember the meaning of Chinese characters. The other four learners build their knowledge by creating symbols comparing Chinese characters with other things which they have seen to help memorize the meaning of 目 $(\mathrm{Mu})$, eye in Chinese language.

The next character is $\square$ (Kue), mouth. Out of fifteen learners, eleven have compared the characteristics of what they have seen with the meaning of the Chinese characters ロ (Kue), mouth. The other four create their knowledge by using their own real experiences to make up a story related to the meaning of the Chinese characters $\square$ (Kue), mouth.

The last character is 手 (Sue), hand. From fifteen learners, five build knowledge of Chinese character recognition by observing teacher who has taught how to write in line order after that remember to create knowledge comparing to the original knowledge to create a picture in the brain. Five learners create their own knowledge by interpreting the meaning of existing 


\section{International Journal of Social Science and Economic Research}

ISSN: $2455-8834$

Volume:06, Issue:07 "July 2021"

knowledge with previous experiences to make reasons to help remember the meaning of Chinese characters. Two build their knowledge by creating symbols to compare Chinese characters with what they have seen to help remember the meaning of 手(Sue), hand. The other two learners build knowledge by interacting with the environment to create stories to connect to Chinese characters to help remember the meaning.

\section{Animals}

The first character is 鸟 (Neu), bird. Out of fifteen learners, eight compare this Chinese character with the one they have seen according to the experience each person has gained until the creation of their own knowledge. Five have built up their knowledge by creating symbols comparing Chinese characters with what they have seen to help remember the meaning of 鸟 (Neu), bird. The other two create knowledge by using interaction with the family to make up a story to relate to the Chinese characters to help remember the meaning.

The next character is 牛 (Niu), cow. From fifteen learners, five have compared the characteristics of this Chinese character to a meaningful picture in order to help them remember to build up their own knowledge. Six learners build the knowledge of Chinese character recognition by observing the teacher who teaches to write it in line order then memorize it to create knowledge to compare with the previous knowledge and bring up images in the brains. Three learners build up knowledge by making up symbols comparing Chinese characters with what they have seen to help them remember. One learner builds his knowledge by using previous experiences he has seen to create a story to help him remember. The other learner builds knowledge by using family interaction to create stories in relation to the Chinese characters to help remember the meaning.

The next character is 马 (Ma), horse. Out of fifteen, ten learners recognize this Chinese character from the same sound as the sound of Mo Ma and five learners remember it by using the characteristics of the Chinese character to compare with the characteristics of the horse they have seen according to the experience each person has which is different.

The last character is 猪 $(\mathrm{Ju})$, pig. From fifteen, eleven learners recognize this Chinese character from the same sound as the vowel sound $U$ and four learners have built their own knowledge from the interpretation of the existing knowledge to the previous experience to give reasons to help remember the meaning of the Chinese character.

\section{The Sky}

The first character is 天 (Tien), the sky. From fifteen learners, twelve learners build up the knowledge of this Chinese character by observing the teacher who teaches the writing in line 


\section{International Journal of Social Science and Economic Research}

ISSN: $2455-8834$

Volume:06, Issue:07 "July 2021"

order then memorize it to build self-knowledge. The other three learners use their previous experiences to create stories to help remember Chinese characters leading to self-knowledge building.

The next character is 月 (Yewee), the moon. From fifteen learners, there are five build the knowledge of this Chinese character recognition by observing the teacher who teaches the writing in line order then remember to build their own knowledge and compare the characteristics of Chinese character with picture to match the meaning. Six learners compare the characteristics of the Chinese character with picture in order to memorize its meaning. And the other four learners have built their knowledge by using existing experiences to create stories to help remember Chinese character which leads to build self- knowledge.

The next character is 日 (Yue), the sun. Out of fifteen learners, five have built their knowledge by comparing the characteristics of the Chinese character with the picture in order to recognize the meaning. Five learners build knowledge by using existing experiences to create stories to help remember Chinese character which leads to self-knowledge. The other five learners have built their knowledge by using existing knowledge to relate to new knowledge to remember the meaning of the Chinese character which is the method for self-knowledge.

The last character is 云 (Yewan), cloud. From fifteen learners, eight have built their knowledge from the use of old knowledge when they are taught by the teacher together with new knowledge. Six children create knowledge by using existing experiences to make up stories to help remember Chinese character leading to self-knowledge creation. The other learner create knowledge by comparing the characteristics of Chinese character with picture in order to memorize their meaning.

\section{Family}

The first character is 爸爸 $(\mathrm{Pa} \mathrm{Pa})$, father. Of fifteen learners, nine build knowledge of vocabulary memorization by comparing sound with the same Thai meaning. Six learners build knowledge by using previous experience to make up stories to help remember Chinese character which lead to self-knowledge creation.

The next character is 妈妈 (Mama), mother. From fifteen learners, ten learners build the knowledge of vocabulary memorization by comparing the sound with the same Thai meaning. The other five use original experience to create a story to help remember the meaning of the Chinese character. 


\section{International Journal of Social Science and Economic Research}

ISSN: $2455-8834$

Volume:06, Issue:07 "July 2021"

The next character is 姐姐 (Jia Jia), older sister. Out of fifteen, four learners build up the knowledge of word recognition by comparing the sound with the same Thai meaning. The other eleven learners create knowledge based on experiences that have ever happened in the daily life of each learner who does not interact with the same environment to make up stories that help create different knowledge.

The last character is 妹妹 (Mei Mei), younger sister. Of fifteen learners, ten have built up their knowledge of symbolic comparison of images that they have imagined with Thai meaning to create their self-knowledge. One learner builds the knowledge of Chinese character by memorizing the line order taught by the teacher to help him remember its characteristics. And the other four learners build their knowledge based on previous experiences in each of their daily life which each of them will not interact with the same environment to make up stories that help create different knowledge.

From the research results above, the researcher gets the conclusion on the process of building knowledge in learning Chinese of early childhood classified into 3 issues: using memorization method, using previous experience / knowledge, and using creation of symbol / imagination as follows

\section{Using Memorization Method}

Learning Chinese is difficult but this research shows that early childhood can simplify it by creating a cognitive-building process by recognizing characters so that they can remember them. They use the cognitive method by observing the teacher who teaches things around them. Learners tend to remember what they actually perceive and one more important reason, Chinese is the language that comes from pictures which has the way of writing in correct line order. This makes early childhood learn how to create Chinese characters. Chinese is remembered writing in line order, it is then used to create knowledge to memorize in the brain.

Early childhood methods of learning and memorizing languages are different from those of adults. The fact that a learner learns language is relevant and involved in brain development very much. Language development must be consistent with brain development. The language that the learner learns must be connected to what he is familiar with, a dream and an imagination. Learners also feel proud in learning language which they can read and speak. Brain and memory will be developed according to structure and function of age, extremely fast in childhood and gradually decline in adulthood (Kowsuwan, 2009). 


\section{International Journal of Social Science and Economic Research}

ISSN: $2455-8834$

Volume:06, Issue:07 "July 2021"

Therefore, language development in early childhood requires that learner must be communicated in his social environment, motivated and encouraged to learn a variety of languages to suit his differences individually to learn languages effectively.

\section{Previous Experience / Prior Knowledge}

If saying according to the principles of the theory of Constructivism, learners will be able to create knowledge by relying on previous experience and prior knowledge. Interpretation of previous experience linked to new knowledge and new experience with the teacher as a facilitator, it was found that learners have a process of building up their knowledge until they can recognize as characters. To use the experiences that have been acquired to build up knowledge depends on what they like or are interested in doing. Learners will not dismiss their effort and will generate different knowledge in accordance with experience and knowledge gained

The learners' experiences will arise from the things surrounding them. Research shows that they are closest to their families. Things that happen within the family are essential in fostering knowledge and experience which leads to the creation of a hundred stories according to which each learner has learned until the process of Constructivism. Therefore, learners have different methods of building up knowledge depending on the experience and knowledge they have gained.

\section{Symbol / Imagination}

The evolution of the writing system of Chinese language is caused by the drawing of ancient people in the ancient time. It is later developed into a complete writing system. The characters use their shapes to express their meaning. Because at the beginning that the Chinese character system begins to adjust the way of writing as picture characters, most of them know what they mean as they are very like real things. Consequently, the writing system of Chinese language is the system that expresses meaning.

In conducting this research, the researcher does not explain to the learners that the Chinese characters are from pictures as well as expressive language. But learners can interpret Chinese characters because each learner can imagine what the Chinese characters they have learned are like from the fact that they have known. When they recognize that, they compare it with Chinese characters and create symbols to help them recognize them. In one Chinese character can create a number of symbols and meanings based on the imagination of each individual learner. If we let them have independent thought, they will have imagination in the brain and be able to build up knowledge on their own. 
International Journal of Social Science and Economic Research

ISSN: 2455-8834

Volume:06, Issue:07 "July 2021"

For the study of the reflection obtained from early childhood Constructivism process, it can be summarized into social, cultural and value issues (Daniels,1996) as follows

\section{Society}

This research found that Chinese language is a tool for cognitive development of learners and at the same time, they improve their Chinese through thinking as well. It allows them to interact socially with their parents, teachers and everything around them which they imagine or remember the experience which has been touched to create knowledge. What each learner reflects from the cognitive-building process is different. In this research, we will see relationship that occurs within families which reflects relationship, love, warmth including various limitation of each family.

Additionally, the research also reflects the social characteristics that learners are exposed until knowledge creation. Learners have been influenced by the environment since their birth which apart from natural environment, there are also social environment, various social institutions starting with family institution that influences the cognitive development of the individual. Learners learn symbols and words for the first time from society. Intelligence in communicating language is the basis which makes them different from other living things. Moreover, language is an important means of thinking and developing advanced intelligence. The cognitive and language development of a learner begins separately but as he grows older, both will be developed together.

\section{Culture}

Learners adapt their thinking and understanding according to their social and cultural experiences until knowledge has been built up. This leads to a higher level of cognitive process. Each culture will pass on its characteristics of beliefs and values to the learners making it known what they think and they should think. Each learner adapts to the culture which he learns and the society where he lives until he can form his knowledge.

From this research, it was found that the cognitive-building process reflects the culture of each individual child. Learners' culture is not created by itself but each learner learns by imitating culture. When that culture has been absorbed, learners learn to adapt and then help themselves build up their knowledge.

\section{Values}

From the research, it was found that the process of cognitive-building knowledge in learning Chinese of early childhood reflects the values of early childhood including eating values; for 


\section{International Journal of Social Science and Economic Research}

ISSN: $2455-8834$

Volume:06, Issue:07 "July 2021"

example, learners will eat as parents do, they will have close relationship with their parents, they are more likely to like what their parents do. This is because the behavior of imitation cultivates eating values. The next one is living values which changes to the time. These reflect the convenience of living as a result of the expansion of technology and industry to a large extent. According to Kowsuwan (2009), with the rapid reception of information and knowledge, learners can learn things around them quickly which affects the process of creating knowledge.

Some of the rapidly changing values in today's society reflects the social problem of parenting that may affect learners in the future. Every value cultivated in the learners if a good one, it should be supported. If the reflection shows inappropriate values, solution should be sought so as not to affect long-term learning.

\section{Discussion of Research Findings}

Based on the results of in-depth interviews to study the self-knowledge process in Chinese learning for early childhood appeared above, the researcher would like to discuss those of the research based on the medium used by learners to build up self-knowledge, namely, language, social interaction, culture, imitation of previous experiences, reinforcement of learning (DixonKrauss, 1996) as follows

\section{Language}

Early childhood language learning is different from adult language learning methods because learners' level of cognitive maturity is not fully developed. They still cannot think of abstraction, cannot make full use of all parts of the body related to language development. These abilities depend on the developmental level of each age. And since language has abstract properties, it needs to use special symbols instead of meaning. Young learners can learn by hearing, listening to the speaking of parents, guardians, or from daily life consistent with the concept of Vygotsky (Wing \& Putney, 2002) expressing his attitude that at the first time language emerged, it did not represent any idea. It was a period of time when thought and language were not related. But when learners develop more, thought and language becomes more interrelated. Thought is expressed through language. That the expressive language becomes more rational is the result of more idea.

\section{Social Interaction}

Self-knowledge theory learning is a process that learners have to deal with information not just receiving information. Not only the learning process of interaction in the brain, it is also a social process. The creation of knowledge is therefore both intellectual and social process. But in the knowledge building of Chinese learning for early childhood, it can be seen that learners use their 


\section{International Journal of Social Science and Economic Research}

ISSN: $2455-8834$

Volume:06, Issue:07 "July 2021"

own social interactions to create knowledge and meaning to help remember the meaning of the Chinese characters. This is in line with Vygotsky's theory quoted in the writing of (Khaemmanee, 2011) that the social interaction of learners with parents, teachers, and others who provide care and help to them allows them to create and learn without limit depending on the social context where they are encouraged to interact with the supportive peers, help in Zone of Proximal Development (Wing \& Putney, 2002) apart from the interaction between experts and trainees.

\section{Culture}

Each learner experiences different lifestyle. Creating learners' knowledge of Chinese depends on the culture of the individual. The learning of each learner reflects the social culture that the individual is exposed to. As mentioned in the writing (Khaemmanee, 2011) that a learner adapts his thinking and understanding according to the experiences gained from his society and culture until knowledge has been built up. This gives them higher mental functions where each culture transmits specific characteristics of beliefs and values getting them to know what they think and how they should think to be appropriate.

\section{Imitation}

Learning language in the early childhood, learners learn language better than adults because they learn to imitate the ability to recognize it. In learning Chinese, they are learners who imitate the voice of the teacher, imitate what they have seen, heard from the material that the teacher has designed in Chinese learning. As explained in the writing by Vygotsky (Wing \& Putney, 2002) that the role of imitation is important to learning and development; for example, if a learner is having a hard time solving a maths problem, the teacher then solves it with an example on the blackboard. At that time he may imitate the teacher's solution by creating understanding within himself. But if the teacher has him solve a more difficult maths problem, an extension of what has been learned to something new, he may not be able to understand at that time. The teacher therefore needs to solve this kind of problem many times so that he imitate the solution gradually.

\section{Previous Experience}

Learners bring their experiences in their lives to help recognize Chinese characters which leads to the creation of knowledge thus making the process of creating knowledge different because they have different experiences. When faced with new learning, learners must rely on previous experiences and prior knowledge to help adjust their learning structures that help recognize Chinese characters. As Vygotsky (Wing \& Putney, 2002) explained that the study of learning is based on two processes of creation. Firstly, learners learn by creating new knowledge by 


\section{International Journal of Social Science and Economic Research}

ISSN: $2455-8834$

Volume:06, Issue:07 "July 2021"

themselves, not only accepting the information that flows into their brain. Knowledge arises from the interpretation of the experience gained. It is noticeable that while we are interested in doing one thing intentionally, we will not stop. We will try to figure out how to fix it. Secondly, the learning process will be the most efficient if that process is meaningful to that learner.

\section{Enhancement of Learning}

In early childhood Chinese learning, the learners adapt and find ways to allow them to recognize Chinese characters differently. Mostly, learners are the doers of knowledge, not teachers or others to supplement them. But the activities that the teacher contributes to the teaching process of the lesson plan help them remember the meaning of the Chinese characters better. As Vykotsky (Wing \& Putney, 2002) mentioned that enhancement of learning can be done in a number of ways, such as exemplification, giving feedback, reflection on learning result, checking the knowledge of the learners by having them tell what they have learned, reducing the complexity of task or learning activity so that it is easier to understand and so on. Where enhancement of learning can be effective, it must be importantly based on understanding of Zone of Proximal Development. From the level of actual development of the learners as the starting point for learning until the highest level of the development that they are able to achieve will enable teachers to properly organize the learning process and make teaching plans suitable for the learners' potential.

\section{Suggestion}

1. Each learner can create his own learning, choose ways to allow himself to remember those knowledge on his own. Consequently, in organizing learning activities, teachers should manage various learning activities to help enhance learning. In order to have learners remember that knowledge, it is important that they should create their knowledge by themselves. If they manage their own knowledge, they remember and understand it better than being told by the teacher.

2. In the next studies, what will be reflected in the learners' learning process should be investigated. In this research, there is reflection in the learning process, but not in the depth of what they want to reflect, whether the action in the family which is very important to the learning process. During childhood, family is extremely important to the development of learning.

\section{References}

Daniels, H. (1996). An Introduction to Vygotsky. London: Routledge.

Dewey, J. (1973). The Philosophy of John Dewey: The Lived Experience. Edited with an introduction by John J. McDermott. New York: Putnam. 
International Journal of Social Science and Economic Research

ISSN: 2455-8834

Volume:06, Issue:07 "July 2021"

Dixon-Krauss, L. (1996). Vygotsky in the Classroom: Meditated Literacy Instruction and Assessment. Reading, MA: Addison Wesley.

Iamsa-At, C. (2005). Process of Organizing Experience for Early Childhood. Surathanee: Rajabhat Surathanee University. (in Thai)

Khaemmanee, T. (2011). Science of Teaching: Knowledge for Organizing an Efficient Learning Process. (14 ${ }^{\text {th }}$ enl. ed.). Bangkok: Chulalongkorn University Press. (in Thai)

Kowsuwan, S. (2009). Psychology of Education. ( $8^{\text {th }}$ ed.). Bangkok: Chulalongkorn University Press. (in Thai)

Masantisuk, R. (2008). Teaching and Learning Chinese Language in Thailand at PrimarySecondary Levels. Bangkok: Center of Chinese Studies, Institute of Asian Studies, Chulalongkorn University. (in Thai)

Ministry of Education. (2003). Curriculum for Early Childhood 2003 (B.E. 2546). Bangkok: Kurusapa. (in Thai)

Niyomtham, S. \& Niyomtham, P. (1997). Development of Language. Bangkok: n.p. (in Thai)

Thamboworn, N. (2006). Development of Thought Process in Early Childhood. Bangkok: Chulalongkorn University Press. (in Thai)

Wing, J. \& Putney, L. (2002). A Vision of Vygotsky. Boston: Allyn \& Bacon 